\title{
IMMUNOHISTOCHEMISTRY OF MATRIX MARKERS IN TECHNOVIT 9100 NEW®- EMBEDDED UNDECALCIFIED BONE SECTIONS
}

\author{
R. Yang ${ }^{1}$, C.M. Davies ${ }^{1}$, C.W. Archer ${ }^{2}$ \& R.G. Richards ${ }^{1 *}$ \\ ${ }^{1}$ AO Research Institute, Davos, Switzerland \\ ${ }^{2}$ Connective Tissue Biology Labs, School of Biosciences, Cardiff University, Wales, UK
}

\begin{abstract}
Trabecular bone is routinely analysed by histomorphological-histometrical and immunohistochemical techniques as means of assessing the differentiation status of bone deposition and growth. Currently few embedding resins exist for which both morphological and immunohistochemical analyses can be performed on mineralised tissue. Paraffin, the standard embedding medium for bone enzyme and immunohistochemistry, can only be used on demineralised tissue, but then trabecular structure may be badly preserved. Methyl methacrylate (MMA), the resin of choice for undecalcified bone histology can only be used for bone immunohistochemistry if the usual, highly exothermic polymerisation procedure is avoided which destroys both, enzyme activity and tissue antigenicity. Consequently, most current practices involve cutting samples in half to be processed in separate embedding media when more than one type of analysis is required. Technovit 9100 New ${ }^{\circledR}$ is a low temperature MMA embedding system that is purported to significantly improve tissue antigenicity preservation allowing polymerisation at $-20^{\circ} \mathrm{C}$. In this study, Technovit $9100 \mathrm{New}{ }^{\circledR}$-embedded undecalcified trabecular bone samples (adult human, young bovine and ovine) yielded immunolabelling with several bone matrix markers and preserved morphological features in $7 \mu \mathrm{m}$ sections when stained with Masson-Goldner, von Kossa, or toluidine blue. Bone samples from all resins used (routine MMA, LR White, Technovit 9100 New ${ }^{\circledR}$ ) were immunolabelled with antibodies against osteocalcin, alkaline phosphatase, osteopontin, osteonectin, bone sialoprotein and procollagen type I amino-terminal propeptide. Technovit $9100 \mathrm{New}{ }^{\circledR}$-embedded bone yielded more reliable immunolabelling of the matrix proteins when compared with heat or cold-cured LR White or standard embedded MMA samples. Technovit 9100 New ${ }^{\circledR}$ provided better routine histology than LR White, and was comparable to MMA. Results demonstrated that Technovit 9100 New ${ }^{\circledR}$ can be used as a low-temperature acrylic resin embedding method for routine undecalcified bone histology, as well as for immunohistochemistry.
\end{abstract}

Key Words: Immunohistochemistry, osteocalcin, osteopontin, bone sialoprotein, alkaline phosphatase, procollagen type I, Technovit $9100 \mathrm{New}{ }^{\circledR}$, acrylate-embedding, undecalcified cancellous bone, histomorphology

*Address for correspondence:

R.G. Richards

AO Research Institute

Clavadelerstrasse

CH 7270 Davos, Switzerland

Telephone Number: ++41 814142397

E-mail: geoff.richards@aofoundation.org

\section{Introduction}

Methyl methacrylate (MMA) has been used with great success for routine undecalcified bone histology for nearly forty years (Schenk 1965, Burkhardt, 1966; Te Velde, 1977). However, enzyme- and immunohistochemistry in MMA embedded sections remains difficult and thus without wide-spread acceptance. This reservation is partly due to MMA's high polymerisation temperatures. It has been recognised for more than thirty years that minimising polymerisation temperatures during the embedding process is critical for preserving a tissue's enzyme activity and antigenicity (Ruddell, 1967). Low-temperature pure MMA embedding has been attempted since 1981 (Westen et al., 1981; Chappard et al., 1987) with differing degrees of success, at different temperatures, and by the addition of different catalysts and accelerators to the monomer MMA resin. Westen et al. (1981) were able to demonstrate enzyme histochemistry in bone marrow biopsies after low temperature MMA embedding. Chappard et al. (1987) embedded large undecalcified bone biopsies and polymerised them at $4^{\circ} \mathrm{C}$ with reportedly excellent TRAP (tartrateresistant acid phosphatase) enzyme preservation. The embedding protocol utilised the chemical initiator N,Ndimethylaniline in addition to the conventional catalyst benzoyl peroxide. However, other laboratories have had difficulty reproducing these initial results and the methodology is tedious (Sanderson, 1997).

Other attempts at developing a more convenient, reliable embedding method were made through the addition of another methacrylate resin, glycol methacrylate (GMA), to the MMA, creating a mixture, and catalysing this mixture with N,N-dimethylaniline and benzoyl peroxide (Chappard et al., 1983; Liu, 1987). This mixture reportedly polymerised at $5^{\circ} \mathrm{C}$ and preserved acid phosphatase activity. However, GMA has the disadvantage of not being removable from the tissue section once attached to the slide so that there is the potential for low sensitivity and reduced clarity of tissue resolution during immunohistochemical and histological procedures. In an in situ hybridisation study comparing samples embedded in Technovit 9100 (low-temperature pure MMA embedding) and Technovit 7100 (low-temperature pure GMA embedding), the MMA samples demonstrated higher in situ hybridisation sensitivity compared with the GMA samples, likely because it was possible to remove the MMA resin from the slide before labelling, thus exposing more binding sites (Saito et al., 1998).

Both groups using MMA/GMA mixtures reported that polymerisation was inhibited at $-20^{\circ} \mathrm{C}$ so that a higher polymerisation temperature had to be utilised (Chappard et al., 1983; Liu, 1987). Technovit $9100 \mathrm{New}{ }^{\circledR}$, on the other hand, a relatively recent low-temperature pure MMA embedding method commercially available since 
2000 , does not demonstrate inhibited polymerisation temperatures at sub-zero degree centigrade levels. Rather, it allows for polymerisation at $-20^{\circ} \mathrm{C}$ without the addition of other monomeric resins like GMA.

Presently, no published work exists for Technovit 9100 New ${ }^{\circledR}$ with bone. Its predecessor Technovit 9100, though, was used for bone histomorphometry with human iliac crest biopsies (Thomsen et al., 1998), polarised light microscopy (LM) dental studies with extracted human teeth (Arnold et al., 1998; 2001; 2003) and morphological studies of porcine coronary arteries (Strehblow et al., 2002) but was never reportedly used for immunohistochemistry or enzyme histochemistry. Previous work with Technovit 9100 demonstrated that since it can be deacrylated (resin dissolved to expose sample epitopes for labelling or staining), it has higher in situ hybridisation sensitivity than glycol methacrylate, which cannot be deacrylated, but is permeable to stains (Saito et al., 1998). This property suggests that Technovit $9100 \mathrm{New}{ }^{\circledR}$ will yield higher immunosensitivity than LR White since LR White like glycol methacrylate, also cannot be deacrylated.

Paraffin is the standard embedding medium for bone immunohistochemistry. Immunolocalisation of osteonectin (ON) (Jundt et al., 1987; Bianco et al., 1988; Park et al., 1996), alkaline phosphatase (ALP) (Bronckers et al., 1987), osteocalcin (OC) (Bronckers et al., 1987; Bronckers et al., 1994; Stafford et al., 1994; Semba et al., 2000; Rauch et al., 2000; Miao et al., 2001) bone sialoprotein (BSP) (Miao et al., 2001) and OC in situ hybridisation (Arai et al., 1993) were all performed in paraffin-embedded decalcified bone. The major disadvantage however of paraffin embedding as compared with plastic embedding is that it requires bone decalcification, a time-consuming process that eliminates essential information about mineralisation and locations of recent bone formation. The major advantage of a routine plastic embedding resin is that it gives the structural integrity one requires for carrying out static and dynamic histomorphometry while allowing for the possibility of attaining immunohistochemical information.

LR White (London Resin Company, Theale, Berkshire, UK) is an aromatic polyhydroxy dimethacrylate resin first demonstrated for immunocytochemical use in the 80's (Newman et al., 1982). It is relatively hydrophilic with a low viscosity and can be polymerised either by heat, or with UV/blue light, or by chemical acceleration/activation (Yoshimura et al., 1986). Heat polymerisation is normally catalysed by benzoyl peroxide, UV/blue light polymerisation normally by a photocatalyst like benzil, and chemically-activated/accelerated polymerisation by N,Ndimethylparatoluidine in conjunction with benzoyl peroxide (Newman and Hobot, 2001). Unlike MMA, LR White is partially miscible with water and can be polymerised even in the presence of $12 \%$ water by volume. Previous work has demonstrated that bone embedded in LR White can be stained with such standard histological methods as toluidine blue, von Kossa, and haematoxylin and eosin (Parker et al., 1999; Vedi et al., 1999; Bhattacharya et al., 2000; Bord et al, 2000; Miao et al., 2001). LR White immunolabelling of bone sialoprotein
(BSP) and osteopontin (OPN) was demonstrated in undecalcfied rat molars (Arana-Chavez et al., 2001). However, one drawback for immunohistochemistry with LR White is that since LR White cannot be deacrylated, only surface epitopes can be labelled (Newman and Hobot, 2001), since antibodies cannot penetrate LR White resin (Brorson et al., 1994).

In this study, routine MMA and LR White embedding (both heat and blue light, cold cured LR White) and Technovit 9100 New ${ }^{\circledR}$ resins were compared for immunohistochemistry and morphology of embedded undecalcified trabecular bone sections, in order to establish which (if any) procedure provided optimal results.

\section{Materials and Methods}

\section{Tissue}

Samples of human, ovine or bovine trabecular bone (cylindrical cores of radius $=5 \mathrm{~mm}$, height $=5 \mathrm{~mm}$ ) were obtained from a 73-year old human female knee (after knee replacement surgery) with patient consent (Ethic Commission of Graubünden, Switzerland, no. 18/02), a 3-4 month-old male calf distal metacarpal (abattoir, Davos, Switzerland), and a 1 year-old ovine female distal femur condyle (AO Research Institute, Davos, Switzerland). Triplicates of samples for each method were always produced.

\section{Processing}

Fresh bone samples were fixed in $50 \mathrm{ml}$ of $70 \%$ ethanol at $4^{\circ} \mathrm{C}$ for 5 days (or alternatively samples were also fixed in freshly made $4 \%$ paraformaldehyde at $4{ }^{\circ} \mathrm{C}$ overnight, but the results with paraformaldehyde fixation are presented elsewhere Yang, 2003). Samples were dehydrated through an ethanol gradient of $70 \%, 80 \%, 90 \%$, $96 \%, 100 \%$ and $100 \%$ ethanol with twelve hours for each step at $4^{\circ} \mathrm{C}$. Samples were defatted in $30 \mathrm{ml}$ of xylene for 12 hours twice at $4^{\circ} \mathrm{C}$ (removing lipids from the tissue to facilitate penetration of the embedding medium) before embedding in either Technovit 9100 New ${ }^{\circledR}$ or MMA resin. In the case of embedding with LR White (cold or heat cured) resin, samples were cleared with ethanol again (since xylene is not miscible with LR White).

\section{Technovit 9100 New ${ }^{\circledR}$ Embedding}

Samples were embedded in the low-temperature embedding system, Technovit $9100 \mathrm{New}{ }^{\circledR}$ (Heraeus Kulzer $\mathrm{GmbH}$, Germany) consisting of monomeric MMA, dibenzoyl peroxide (catalyst 1), N,N-3,5tetramethylaniline (catalyst 2), decane-1-thiol (regulator), and polymethylmethacrylate (PMMA) powder. Infiltration and polymerisation solutions were prepared as follows: $750 \mathrm{ml}$ of the $1 \mathrm{~L}$ of Technovit $9100 \mathrm{New}{ }^{\circledR}$ stabilised basic solution was destabilised in order to make the infiltration and polymerisation solutions. Destabilisation was performed by the following method: 1) A MILLEXGS $0.22 \mathrm{~mm}$ filter (Millipore, Billerica, MA, USA) was fitted onto a $60 \mathrm{ml}$ syringe. 2) $20 \mathrm{~g}$ of aluminium oxide was poured into the syringe. 3 ) The syringe was filled to 
the $50 \mathrm{ml}$ mark with stabilised basic solution. 4) The top of the syringe was fitted in place. 5) The syringe was held over a labelled glass bottle, and the solution pushed through the syringe into the bottle. Steps 3-5 were repeated until 750 $\mathrm{ml}$ of solution was destabilised. The filter was changed periodically. Infiltration and polymerisation solutions were prepared (Table 1).

After bone samples were defatted in xylene, they were infiltrated in Technovit 9100 New ${ }^{\circledR}$ solutions as follows: Xylene/Technovit $9100 \mathrm{New}{ }^{\circledR}$ basic solution overnight (or 12 hour equivalent) at $4^{\circ} \mathrm{C}$ followed by pre-infiltration in solution 1 for 24 hours at $4^{\circ} \mathrm{C}$ then pre-infiltration in solution 2 for 24 hours at $4^{\circ} \mathrm{C}$ and then infiltration in the final infiltration solution for $3-5$ days at $4^{\circ} \mathrm{C}$. Polymerisation was performed by mixing polymerisation solutions $\mathrm{A}$ and $\mathrm{B}$ (made according to Technovit 9100 New ${ }^{\circledR}$ brochure) immediately prior to polymerisation. Samples were placed in polymerisation moulds (Semadeni AG, Ostermundigen, Switzerland, product no. 1661) and each filled with approximately $3 \mathrm{ml}$ of polymerisation solution (three-fourths to the top). Samples were polymerised at $-20^{\circ} \mathrm{C}$ for $5-7$ days.

\section{MMA Embedding}

Bone samples (as above) were embedded in MMA following xylene clearing/defatting and were infiltrated in: $40 \mathrm{ml}$ uncatalysed monomeric MMA overnight at $4{ }^{\circ} \mathrm{C}$ followed by $40 \mathrm{ml} 2 \%$ benzoyl peroxide-catalysed MMA for 5 days at $4{ }^{\circ} \mathrm{C}$. The polymerisation mixture was prepared by mixing $100 \mathrm{ml}$ monomeric MMA resin with $4 \mathrm{~g}$ dehydrated benzoyl peroxide and $25 \mathrm{ml}$ dibutyl phthalate softener. Samples were placed in the polymerisation mixture for 20 days at $4^{\circ} \mathrm{C}$ and in a $20^{\circ} \mathrm{C}$ water bath for 1 day whereby polymerisation was finally achieved.

\section{LR White Embedding:}

Following defatting, samples were cleared in $30 \mathrm{ml}$ of absolute ethanol for 12 hours twice at $4^{\circ} \mathrm{C}$. Ethanol-cleared samples were infiltrated in either $30 \mathrm{ml}$ of fresh $2 \%$ benzilcatalysed hard-grade LR White (for cold-curing) or 30ml fresh $2 \%$ benzoyl peroxide-catalysed hard-grade LR White (for heat-curing). The optimal grade of LR White resin hardness for undecalcified bone embedding was previously determined to be hard-grade LR White (Yang, 2003). Hard-grade LR White demonstrated on average less bone shattering than medium-hard, medium, or medium-soft grade LR White (Yang, 2003). Infiltration was carried out at $4{ }^{\circ} \mathrm{C}$ for seven days and infiltrating samples were wrapped in aluminium foil to prevent degradation by light exposure or premature polymerisation of the resin. To facilitate infiltration, a vacuum of 200 mbar pressure for 15 minutes was applied on alternate days to the bone samples using a standard dessicator and vacuum pump with pressure gauge. Fresh $2 \%$ benzil-catalysed or benzoyl-peroxide-catalysed hardgrade LR White resin was prepared by adding $9.9 \mathrm{~g}$ of benzil or benzoyl peroxide catalyst to $500 \mathrm{ml}$ uncatalysed hard-grade LR White resin. This was stirred overnight at $4^{\circ} \mathrm{C}$ and wrapped in aluminium foil to shield it from light. When kept at $4^{\circ} \mathrm{C}$ and wrapped in aluminium foil to shield it from light, catalysed LR White has a shelflife of 1 year.

Cold-curing. Samples were placed in polymerisation moulds and filled with fresh $2 \%$ benzil-catalysed LR White. Polymerisation was activated with blue light at $-20^{\circ} \mathrm{C}$ for 24 hours using the automatic freeze substitution machine (Leica Microsystems, Wetzlar, Germany) and a blue light lamp. Polymerised blocks were kept in a cool, dry, dark cabinet for long-term storage.

Heat-curing. Samples were placed in polymerisation moulds and filled with fresh $2 \%$ benzoyl peroxidecatalysed LR White. A layer of paraffin oil was added above the LR White to exclude oxygen. Polymerisation was initiated at $50^{\circ} \mathrm{C}$ for approximately 24 hours.

\section{Sectioning and deacrylation}

Seven $\mu \mathrm{m}$ sections (Polycut E microtome fit with a size D blade at a blade angle of $0^{\circ}$; Leica Microsystems) of Technovit $\AA$, MMA or LR White were stretched with $70 \%$ ethanol on Superfrost Plus slides (Erie Scientific,

Table 1. Preparation of Technovit $9100 \mathrm{New}{ }^{\circledR}$

\begin{tabular}{|l|l|l|l|l|l|l|l|l|l|}
\hline Solutions & xylene & $\begin{array}{l}\text { stabilised } \\
\text { basic soln }\end{array}$ & $\begin{array}{l}\text { destabilised } \\
\text { basic soln }\end{array}$ & $\begin{array}{l}\text { P M M A } \\
\text { Powder }\end{array}$ & $\begin{array}{l}\text { C1 (dibenzoyl } \\
\text { peroxide) }\end{array}$ & C2 & R & store & Special Instructions / Notes \\
\hline $1^{*}$ & $60 \mathrm{ml}$ & $60 \mathrm{ml}$ & & & & & & $4^{\circ} \mathrm{C}$ & Mixes immediately \\
\hline $2^{*}$ & & $100 \mathrm{ml}$ & & & $0.5 \mathrm{~g}(0.5 \%)$ & & & $4^{\circ} \mathrm{C}$ & Dissolves in minutes \\
\hline $3^{*}$ & & & $150 \mathrm{ml}$ & & $0.75 \mathrm{~g}(0.5 \%)$ & & & $4^{\circ} \mathrm{C}$ & Dissolves in minutes \\
\hline $4^{*}$ & & & $150 \mathrm{ml}$ & $12 \mathrm{~g}$ & $0.6 \mathrm{~g}(0.4 \%)$ & & & $4^{\circ} \mathrm{C}$ & Cloudy. Stirred overnight @ $4^{\circ} \mathrm{C}$. \\
\hline Poly A* $^{*}$ & & $360 \mathrm{ml}$ & $57.6 \mathrm{~g}$ & $\begin{array}{l}2.16 \mathrm{~g}(0.5 \% \text { in } \\
\text { final polymeri- } \\
\text { sation mixture) }\end{array}$ & & & $4^{\circ} \mathrm{C}$ & Cloudy. Stirred overnight @ $4^{\circ} \mathrm{C}$. \\
\hline Poly B* $^{*}$ & & & $40 \mathrm{ml}$ & & & $3.2 \mathrm{ml}$ & $1.6 \mathrm{ml}$ & $4^{\circ} \mathrm{C}$ & Mixes immediately \\
\hline
\end{tabular}

*Solutions $1-4$ are infiltration solutions. Poly A and Poly B are polymerisation solutions which must be mixed up in the ratio of 9A:1B immediately before use. (The shelf-life of stabilised Technovit 9100 New ${ }^{\circledR}$ basic solution and the other components of the Technovit $9100 \mathrm{New}{ }^{\circledR}$ kit is 3 years. The shelf-life of destabilised Technovit $9100 \mathrm{New}{ }^{\circledR}$ is 7 days at $4^{\circ} \mathrm{C}$, or 14 days at $-20^{\circ} \mathrm{C}$.) $\mathrm{C}$ - Catalyst, $\mathrm{C} 1=$ dibenzoyl peroxide, $\mathrm{C} 2=\mathrm{N}, \mathrm{N}-3,5-$ tetramethylaniline, $\mathrm{R}$ - Regulator, decane-1-thiol. 
Portsmouth, NH) and dried overnight at $50^{\circ} \mathrm{C}$. Resins were evaluated histologically with Masson-Goldner, toluidine blue, and von Kossa stains. The quality of the histology of Technovit $9100 \mathrm{New}{ }^{\circledR}$ and LR White was compared against the MMA standard resin. MMA and Technovit 9100 New ${ }^{\circledR}$ sections were first deacrylated to improve stain penetration into the specimen. Sections were immersed in MEA (1-acetoxy-2-methoxy-ethane) for 2 x 30 minutes followed by xylene $2 \times 5$ minutes, then through a graded ethanol series for 5 minutes each from absolute ethanol, $96 \%, 70 \%, 50 \%$, to $20 \%$ ethanol.

\section{Morphological Staining}

Trichrome Masson-Goldner. Samples were placed in Weigert's haematoxylin stain for 1 hour, rinsed under lukewarm water for 5 minutes, immersed in Masson solution for 15 minutes, rinsed in $1 \%$ acetic acid (fresh) before being placed in phosphomolybdic acid - orange $\mathrm{G}$ for 10 minutes. Samples were rinsed in $1 \%$ acetic acid, immersed in $0.1 \%$ Light green SF yellowish for $15 \mathrm{~min}-$ utes, rinsed in $1 \%$ acetic acid then de-ionised water, $96 \%$ ethanol, absolute ethanol ( $2 \times 2$ minutes), rinsed in xylene and then immersed in xylene for 30 minutes and mounted with Eukitt (O. Kindler GmbH \& Co., Freiburg, Germany). Three other variations of this method were tried (Variations 1. Using Verhoeff's haematoxylin, 2. Reducing staining time of Verhoeff's haematoxylin and 3. Using Mayer's haematoxylin) and are reported elsewhere, as the results with these variations were not as good (Yang, 2003).

Calcium-salt stain after von Kossa. Samples were immersed for 60 minutes in 5\% aqueous silver nitrate solution (prepared fresh) in light, rinsed in de-ionised water, immersed in 3\% pyrogallol for 7.5 minutes, rinsed in de-ionised water, immersed in 5\% sodium thiosulfate for 7.5 minutes, rinsed in running water followed by rinsing in de-ionised water. Samples were counter stained in $0.1 \%$ aqueous neutral red for 2 hours, rinsed in de-ionised water and then $96 \%$ ethanol, absolute ethanol ( $2 \times 3$ minutes), followed by immersion in xylene for 5-10 minutes and mounted with Eukitt. One other variation of this method was tried (Safranin O variation) but is not reported in this paper since the results were not as good (Yang, 2003).

Toluidine blue. Samples were stained with $1 \%$ toluidine blue for 20 (Technovit $9100 \mathrm{New}{ }^{\circledR}$ or MMA) or 40 minutes (LR White), rinsed in water for 5 minutes followed by $96 \%$ ethanol for $5-10$ seconds, rinsed in absolute ethanol ( 2 x 3 minutes), rinsed in xylene for 30 minutes and mounted with Eukitt.

\section{Immunohistochemistry}

Antibodies. Monoclonal mouse antibodies ( $\mathrm{IgG}$ ) against Osteonectin (ON), Alkaline phosphatase (ALP) and Pro-collagen type 1 aminopropeptide (PINP), were obtained from the Developmental Studies Hybridoma Bank under the auspices of the NICHD and the University of Iowa, Department of Biological Sciences, Iowa City, IA 52242, USA: AON-1 (monoclonal mouse anti-bovine bone osteonectin) (Bolander et al., 1989); B4-78 (monoclonal mouse anti-human bone alkaline phosphatase) (Lawson et al., 1985); SP1.D8 (monoclonal mouse anti-ovine procollagen type I aminopropeptide) (Foellmer et al., 1983). Polyclonal rabbit antibodies against
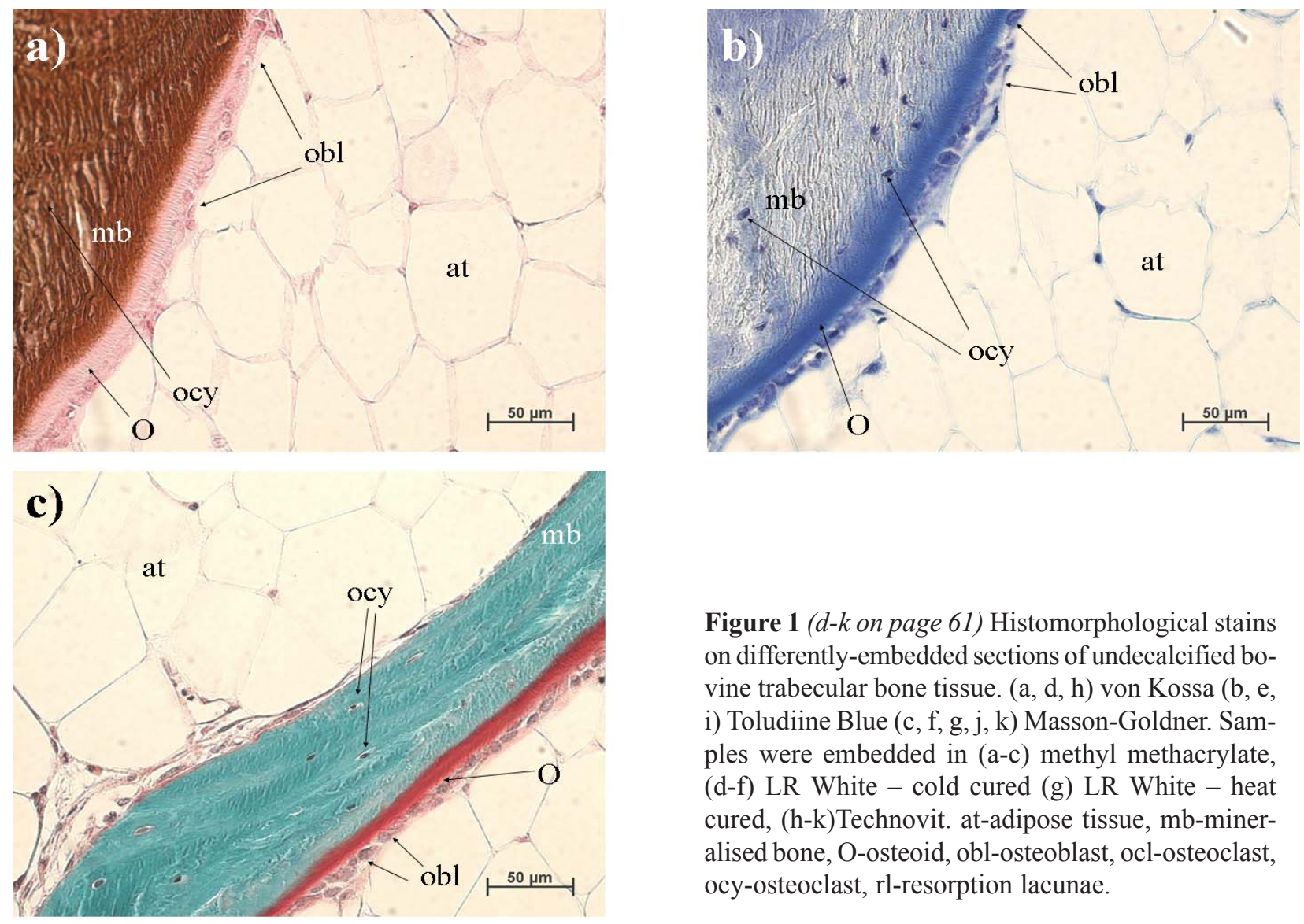

Figure 1 ( $d-k$ on page 61) Histomorphological stains on differently-embedded sections of undecalcified bovine trabecular bone tissue. ( $a, d, h$ ) von Kossa (b, e, i) Toludiine Blue (c, f, g, j, k) Masson-Goldner. Samples were embedded in (a-c) methyl methacrylate, (d-f) LR White - cold cured (g) LR White - heat cured, (h-k)Technovit. at-adipose tissue, mb-mineralised bone, O-osteoid, obl-osteoblast, ocl-osteoclast, ocy-osteoclast, rl-resorption lacunae. 
d)
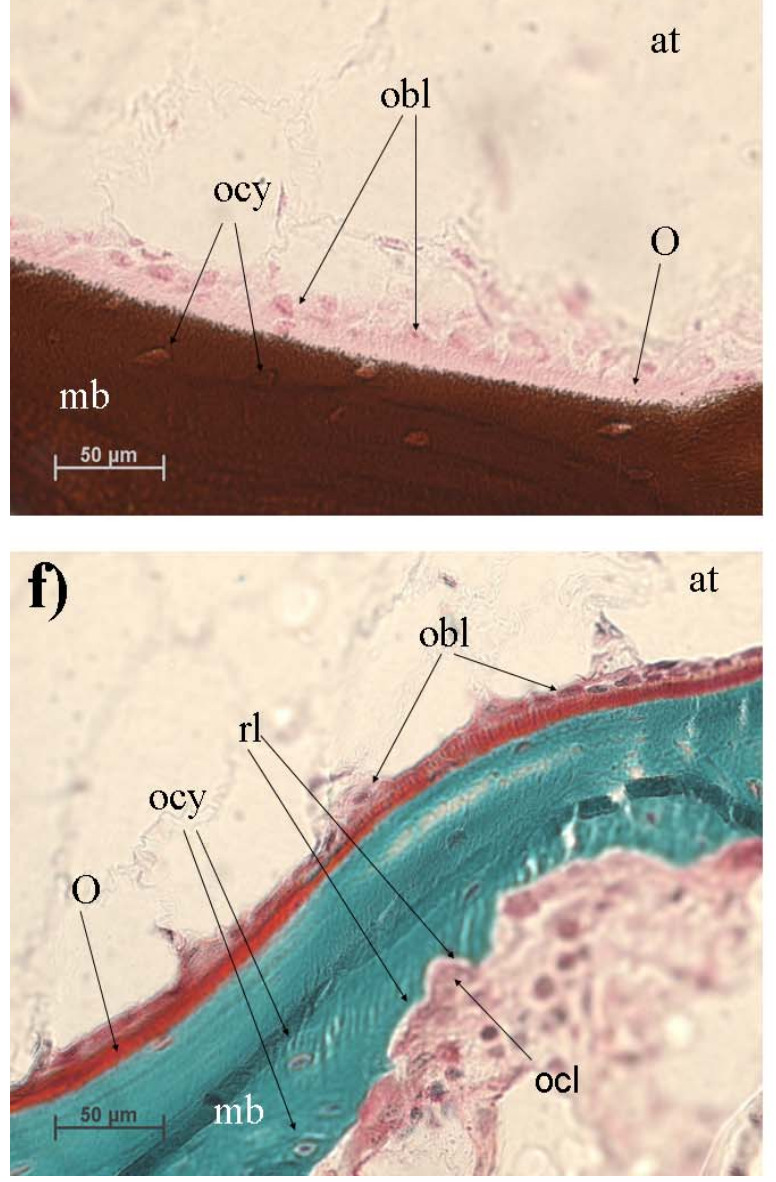

h)
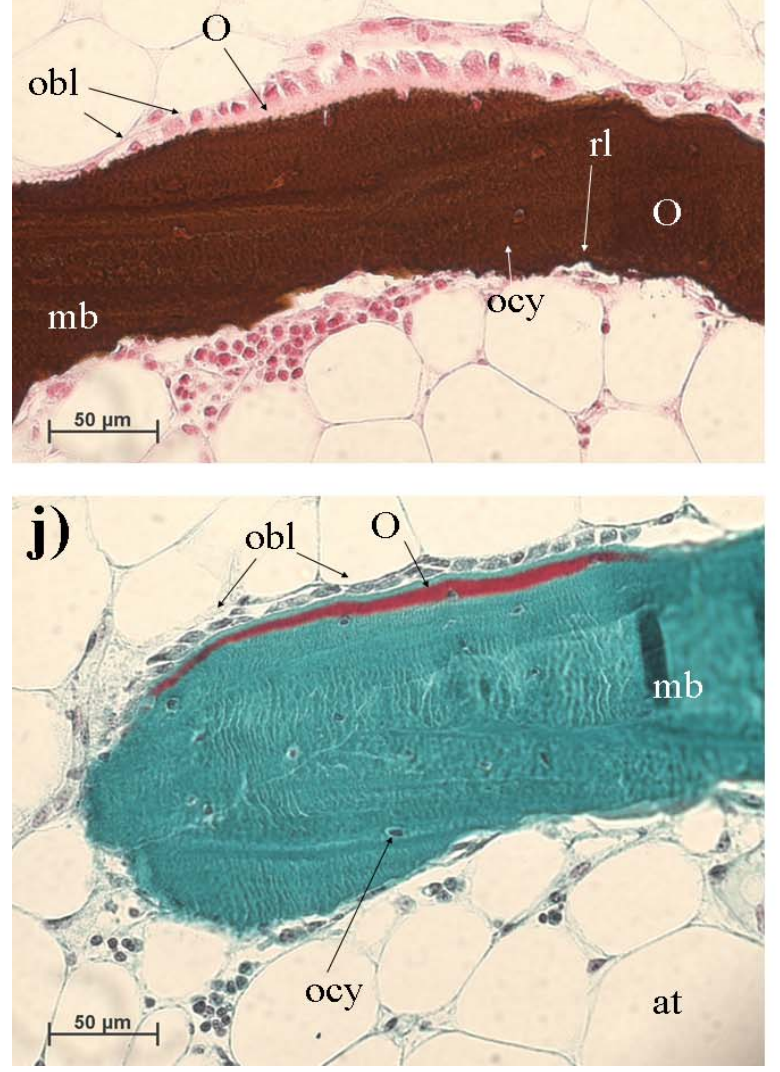

e)
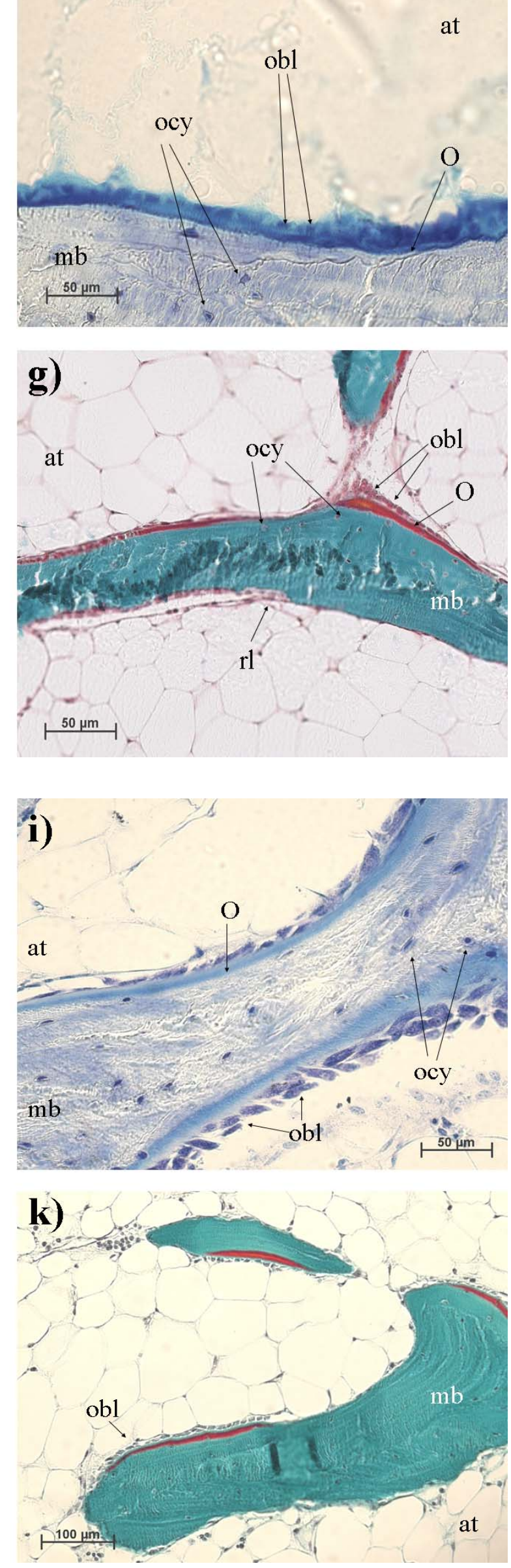
osteocalcin (OC), osteopontin (OPN), and bone sialoprotein (BSP) were generous gifts from Dr. Larry W. Fisher of the National Institutes of Health, National Institute of Dental and Craniofacial Research, Craniofacial and Skeletal Diseases Branch, Bethesda, MD, USA: LF-32 (polyclonal rabbit anti-bovine bone osteocalcin) (Ingram et al., 1993); LF123 (polyclonal rabbit anti-human osteopontin) (Fisher et al., 1995); LF-120 (polyclonal rabbit anti-human bone sialoprotein (Fisher et al., 1995). Mouse immunoglobulins (IgG) were purchased from Sigma (St. Louis, MO, USA) (I8765). Several concentrations and several other antibodies against the same bone matrix markers from other vendors were tested, but are reported elsewhere (Yang, 2003).

Immunolabelling. The method was based on the immunolabelling method of Richards et al. (2001) for immunolabelling of vinculin in focal adhesion sites of cultured cells. The rinsing buffer was $0.1 \mathrm{M}$ PIPES (Piperazine-NN'-bis-2-ethane sulphonic acid) buffer ( $\mathrm{pH} 7.4$ ) $+0.1 \%$ Tween $20+1 \%$ BSA (bovine serum albumin) + $1 \%$ goat serum. This was used for all washes and to dilute the primary and secondary antibodies as well as to prepare the $6 \%$ goat serum. MMA and Technovit 9100 New ${ }^{\circledR}$ sections were first deacrylated with 2-methoxyethyl acetate, cleared through ethanol and rehydrated to distilled water through a decreasing ethanol series. Sections were encircled with a water-repellant wax pen (Daido Sangyo Co., Tokyo, Japan) and slides were placed in a humidified chamber containing moist tissue. The procedure was carried out at room temperature $\left(20-22^{\circ} \mathrm{C}\right)$ unless otherwise stated. The volume of each wash and incubation was $200 \mu \mathrm{L}$.

The immunolabelling procedure was as follows: Sections were washed 6 times with rinsing buffer each time followed by $6 \%$ goat serum for 15 minutes to block nonspecific binding by the primary antibody and tipped off.

For Technovit $9100 \mathrm{New}{ }^{\circledR}$ in all three species: Primary antibodies were incubated for $1 \mathrm{hr}$ at $21^{\circ} \mathrm{C}$ and diluted between $3 \mu \mathrm{g} / \mathrm{ml}-10 \mu \mathrm{g} / \mathrm{ml}$ IgG for optimal working concentrations. For MMA: polyclonal anti bovine OC (LF-32, 1:100, $10 \mu \mathrm{g} / \mathrm{ml}$ ) was incubated overnight at $4{ }^{\circ} \mathrm{C}$ and used at three times the working concentration of Technovit 9100 New ${ }^{\circledR}$ sections.

Sections were immunolabelled with either monoclonal mouse anti-ALP, anti-ON, or anti-PINP antibodies being incubated for 2 hours at room temperature with a $5 \mathrm{~nm}$ gold-conjugated goat anti-mouse secondary antibody (1:200). Sections immunolabelled with either polyclonal rabbit anti-OC, anti-OPN, or anti-BSP antibodies were incubated for 2 hours at room temperature with a $5 \mathrm{~nm}$ gold-conjugated anti-rabbit secondary antibody (1:200). Sections were washed 6 times with rinsing buffer each time. Sections were incubated with $1 \%$ glutaraldehyde in PIPES pH 7.4 for 5 minutes to keep the gold conjugates from dissociating, followed by being washed 3 times with PIPES and rinsing with distilled water. Sections were silver enhanced (silver enhancement kit, British Biocell International, Cardiff, UK) for $30 \mathrm{~min}$. The reaction was stopped by placing the slides in distilled water for $5 \mathrm{~min}$. No counterstaining was used. Slides were dehydrated through a graded series of ethanol, cleared in xylene and Eukitt-mounted.

\section{Results}

\section{Morphology}

In general bone morphology was well-preserved with well-differentiated cellular constituents (mineralised bone, osteoid, osteoblasts, osteocytes, blood vessels and adipose tissue) in all three resin types (Fig. 1). Standard embedded MMA histology (Fig. 1a-c) was comparable to that of Technovit 9100 New ${ }^{\circledR}$ (Fig.1h-k) and heat cured LR White (Fig. 1g) and these three all preserved undecalcified bone histology better than cold cured LR White (Fig. 1df). There was no significant tissue shrinkage or disruption of the mineralised bone from sectioning using either MMA or Technovit 9100 New ${ }^{\circledR}$ embedding methods. (Fig. 1). Cold-cured LR White displayed inferior histomorphological detail, compared to that of heat-cured LR White since samples embedded in cold-cured LR White displayed poor histomorphological detail of the soft tissue (Fig. 1). Soft tissue shrinkage could also be observed with the cold-cured LR White embedded samples.

Von Kossa staining provided good differentiation between mineralised (dark brown to black) and unmineralised (pink) matrix, cells and soft tissues (Fig. 1a,d,h). Technovit 9100 New ${ }^{\circledR}$ provided better morphological staining than LR White. In Technovit, osteoblasts lining osteoid, haematopoietic tissue (dark pink) and adipocytes (dark pink) within the bone marrow and osteocytes (pink) within the mineralised bone were easily identifiable beside the mineralised bone (dark brown) (Fig.1h). It was more difficult to distinguish between the osteoblasts and the osteoid in MMA embedded samples (since in these samples they were both similar shades of pink) than in Technovit $9100 \mathrm{New}{ }^{\circledR}$ embedded samples (Fig. 1a). In LR White, osteoblasts and osteoid were also both weakly stained, and adipocytes and haematopoietic tissue were not visible at all (Fig.1d).

Technovit 9100 New ${ }^{\circledR}$ sections stained with toluidine blue (Fig. 1i) demonstrated clear differentiation of osteoblasts (dark blue), osteoid (sky blue), mineralised bone (light blue), osteocytes (dark blue) and adipose tissue (light blue). MMA (Fig. 1b) and LR White (Fig. 1e) stained with toluidine blue displayed a similar colour intensity of staining for the osteoid and the osteoblasts so that it was more difficult to distinguish between the two on first view.

Masson-Goldner (Fig. 1c,f,g,j,k) demonstrated clear differentiation between mineralised and unmineralised matrix in all three resins. In Technovit 9100 New ${ }^{\circledR}$, it provided excellent differentiation between osteoid (red), mineralised bone (green) osteoblasts, haematopoietic tissue and osteocytes (which all were greyish-green), (Fig. 1j,k). In LR White (cold and heat-cured), (Fig. 1f,g) and MMA (Fig. 1c), the Masson-Goldner stain also also provided clear differentiation between osteoid (red), mineralised bone (green) and osteoblasts (red-orange). The heat cured LR White showed much better preservation than the cold-cured LR White following application of MassonGoldner (Fig. 1f,g). 

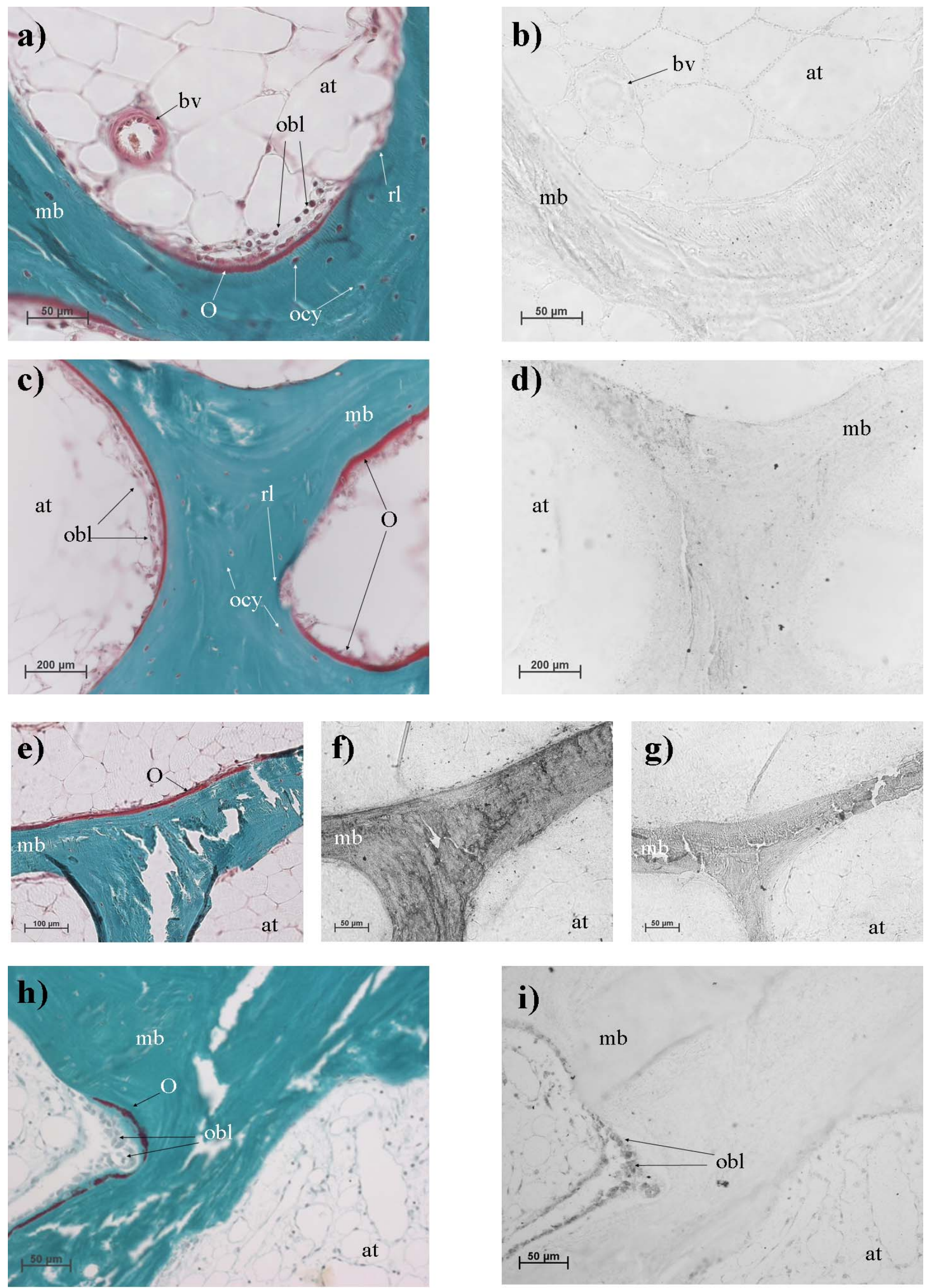

Figure 2 Masson-Goldner staining and OC-immunoreactivity on serial sections of human trabecular bone after (a, b) methyl methacrylate, (c, d) LR White - cold cured (e, f, g) LR White - heat cured and (h, i) Technovit 9100 New ${ }^{\circledR}$ resin embedding. Human bone sections were immunolabelled at $4^{\circ} \mathrm{C}$ with osteocalcin. (a, c, e, h) Masson-Goldner stained. (b, d, g) $10 \mu \mathrm{g} / \mathrm{ml}$ overnight labeling, (f) $20 \mu \mathrm{g} / \mathrm{ml}$ overnight, (i) $3.3 \mu \mathrm{g} / \mathrm{ml}$ for $1 \mathrm{hr}$ at $21^{\circ} \mathrm{C}$. bm-bone marrow, bvblood vessel, mb-mineralised bone, O-osteoid, obl-osteoblast, ocy-osteoclast, rl-resorption lacunae. 


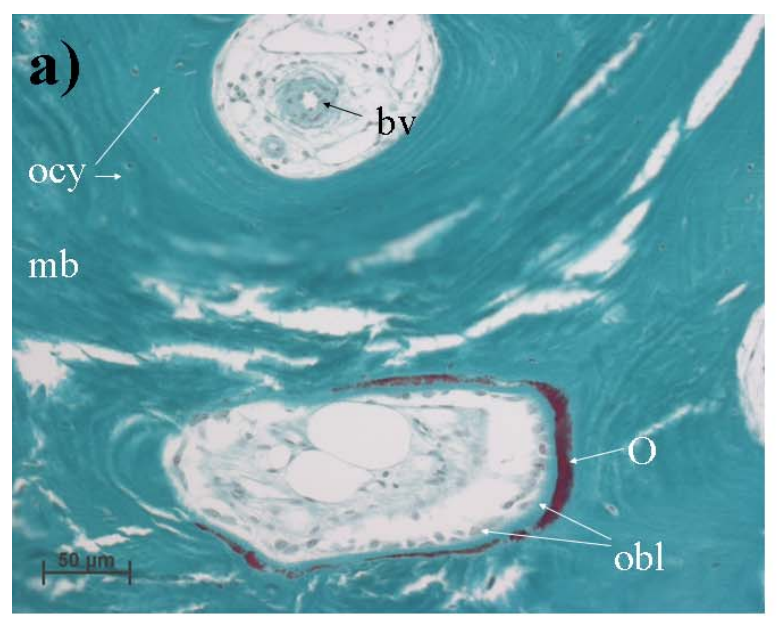

c)
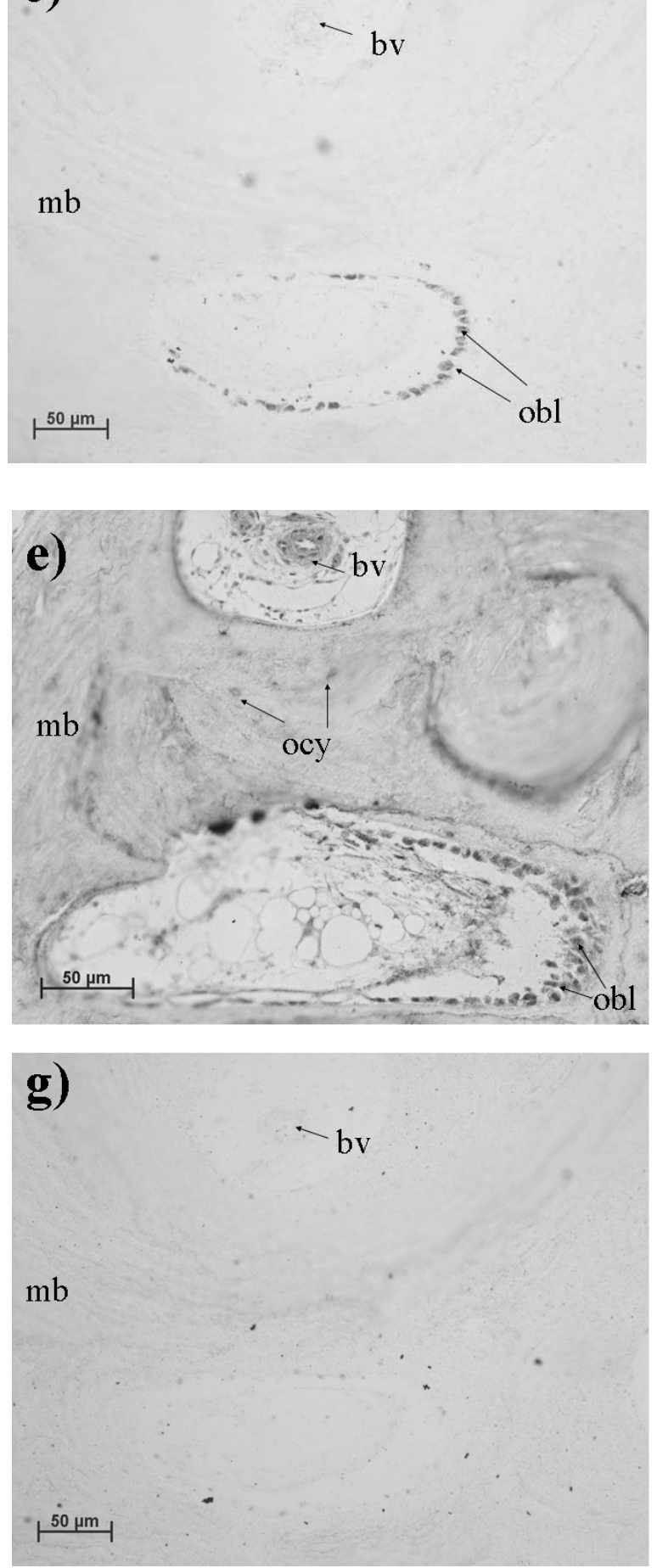
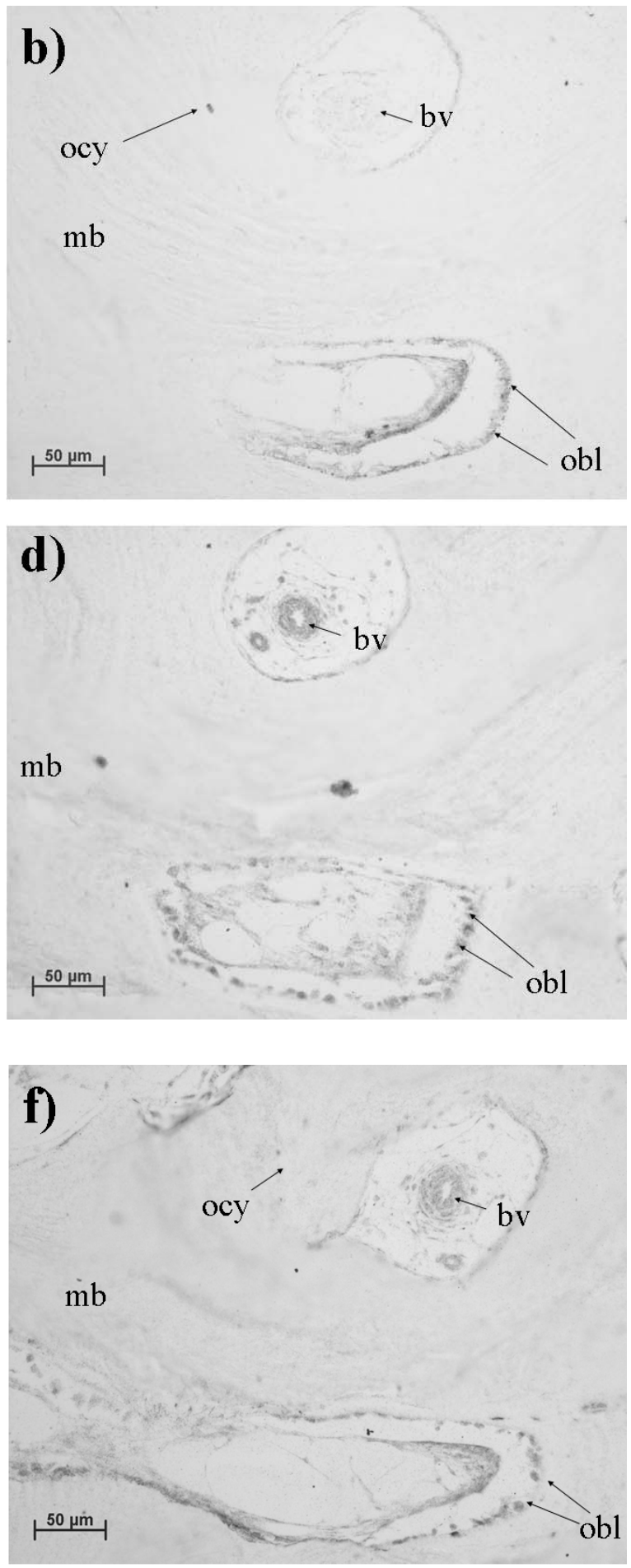

h)

$$
-\mathrm{bv}
$$

$\mathrm{mb}$

$150 \mu \mathrm{m}$ 

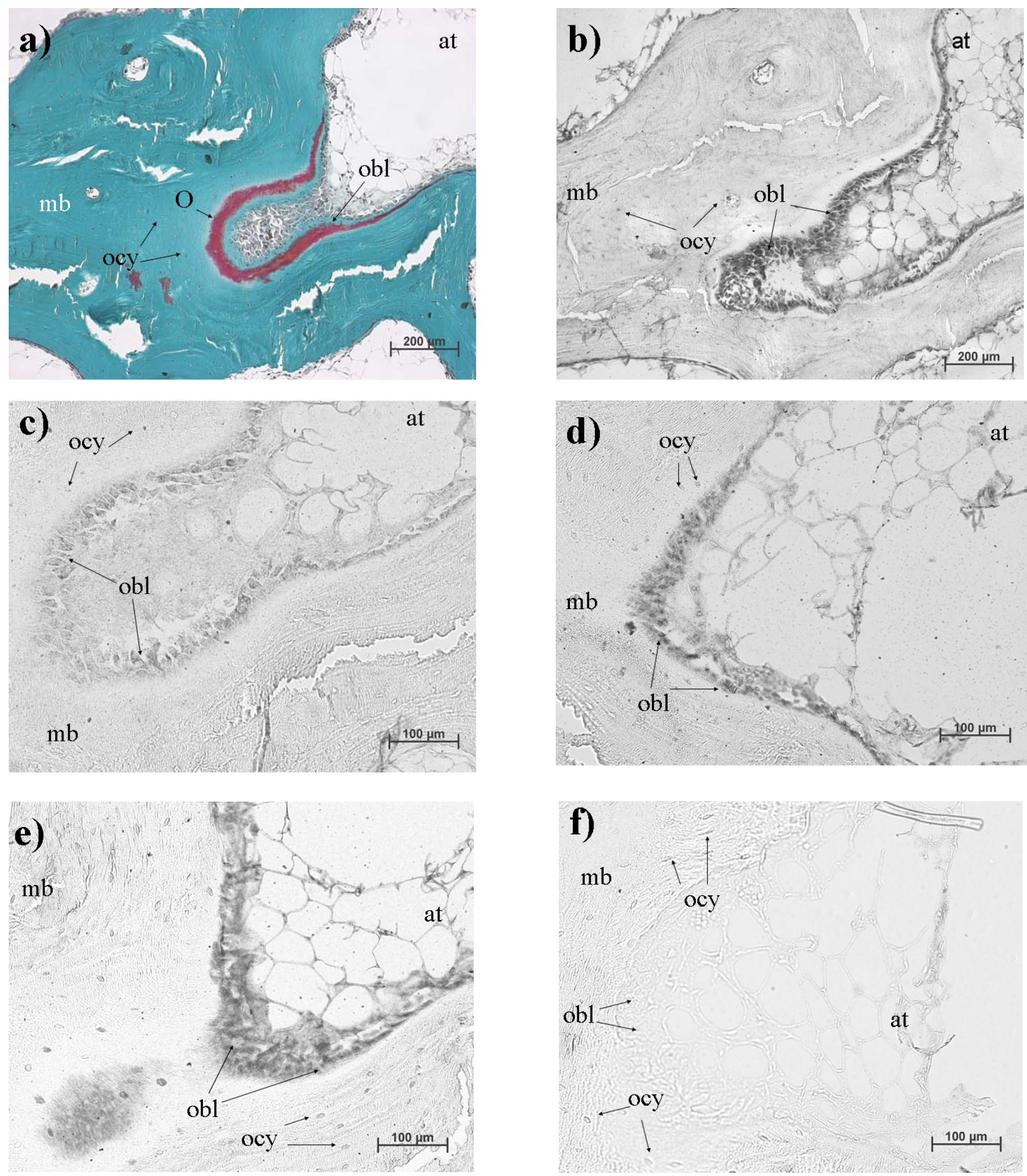

Figure 4(a-f) Staining and immunolabelling of bovine (a-f) trabecular bone embedded in Technovit 9100 New®. (a) Masson-Goldner stained, (b) osteocalcin $(10 \mu \mathrm{g} / \mathrm{ml}$ polyclonal rabbit anti-bovine), (c) PINP (7 $\mathrm{gg} / \mathrm{ml}$ monoclonal mouse anti ovine), (d) osteonectin $(8 \mu \mathrm{g} / \mathrm{ml}$, monoclonal mouse anti bovine), (e) osteopontin $(10 \mu \mathrm{g} / \mathrm{ml}$ polyclonal rabbit antihuman), (f) no primary antibody. bm-bone marrow, mb-mineralised bone, O-osteoid, obl-osteoblast, ocy-osteoclast.

Figure 3 (page 64) Staining and immunolabelling of human trabecular bone serial sections embedded in Technovit 9100 New®. (a) Masson-Goldner stained. (b-h) Immunolabelled (b) ALP (10 $\mu \mathrm{g} / \mathrm{ml}$, monoclonal mouse anti human), (c) PINP $(7 \mu \mathrm{g} / \mathrm{ml}$ monoclonal mouse anti ovine), (d) osteonectin $(8 \mu \mathrm{g} / \mathrm{ml}$, monoclonal mouse anti bovine), e) osteopontin $(3 \mu \mathrm{g} / \mathrm{ml}$ polyclonal rabbit anti-human), (f) bone sialoprotein $(10 \mu \mathrm{g} / \mathrm{ml}$ polyclonal rabbit anti-human) g) no primary antibody and h) primary antibody replaced with mouse immunoglobulins $(10 \mu \mathrm{g} / \mathrm{ml})$. bv-blood vessel, mb-mineralised bone, O-osteoid, obl-osteoblast, ocy-osteoclast. 

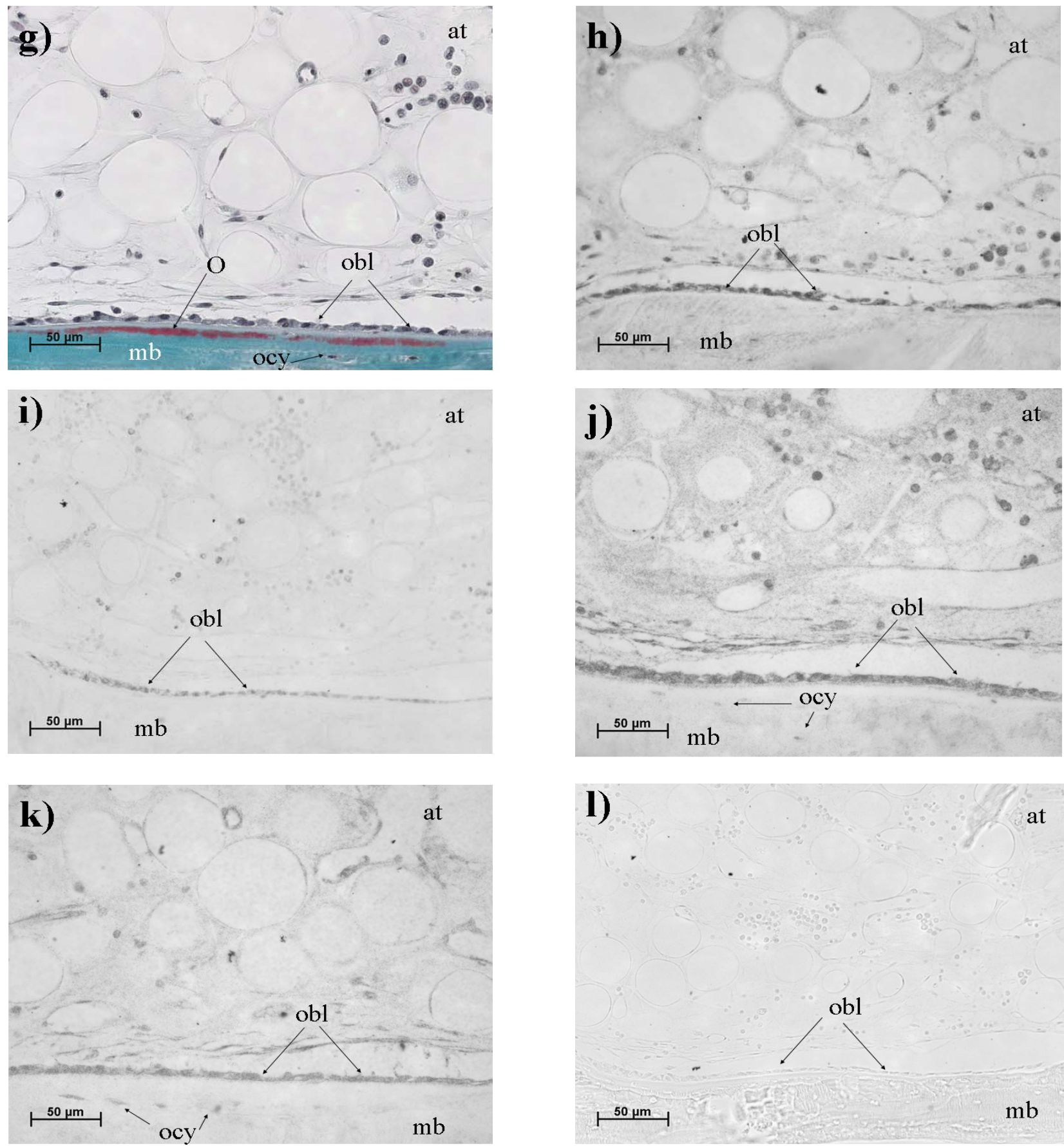

Figure 4(g-l) Staining and immunolabelling of ovine trabecular bone embedded in Technovit 9100 New ${ }^{\circledR}$. (g) MassonGoldner stained, (h) osteocalcin $(10 \mu \mathrm{g} / \mathrm{ml}$ polyclonal rabbit anti-bovine), (i) PINP $(7 \mu \mathrm{g} / \mathrm{ml}$ monoclonal mouse anti ovine), (j) osteonectin $(8 \mu \mathrm{g} / \mathrm{ml}$, monoclonal mouse anti bovine), (k) osteopontin $(10 \mu \mathrm{g} / \mathrm{ml}$ polyclonal rabbit antihuman), (1) no primary antibody. bm-bone marrow, mb-mineralised bone, O-osteoid, obl-osteoblast, ocy-osteoclast.

\section{Immunohistochemistry}

The Masson-Goldner staining method was applied to sections of adult human immediately adjacent to immunolabelled sections so that approximate immunolocalisation in various tissue constituents could be correlated (Fig. 2a,c,e,h). With all three resins (both heat or cold-cured for LR White) the mineralised bone, osteoid, osteoblasts, osteocytes and haematopoietic tissue or blood vessels could be observed. Osteoblasts and haematopoietic tissue from Technovit 9100 New ${ }^{\circledR}$ sectioned adult human bone showed immunoreactivity for OC (Fig. 2i) with very low background labelling. Neither osteoblasts nor haematopoietic tissue from standard MMA-embedded (Fig. 2b), embedded adult human bone showed immunoreactivity with OC. OC-immunolabelled human osteoblasts were evident in heat-cured LR White (Fig. 2f,g) but not in cold-cured LR White (Fig 2d). With heat-cured LR White, the polyclonal antibodies anti-bovine OC (Fig 2f) $(20 \mu \mathrm{g} / \mathrm{ml})$ demonstrated strong background labelling of human bone. In an attempt to reduce the non-specific labelling, antibodies were used at higher dilutions $(10 \mu \mathrm{g} /$ $\mathrm{ml})$, but then osteoblast immunolabelling signal was lost 
Table 2. Antibody immunoreactivity between species

\begin{tabular}{|c|c|c|c|c|c|c|}
\hline Species & {$[\mathrm{OC}]$} & [OPN] & [PINP] & {$[\mathrm{ON}]$} & {$[\mathbf{A L P}]$} & [BSP] \\
\hline Human & $\begin{array}{c}3.3 \mu \mathrm{g} / \mathrm{ml} \\
+++\end{array}$ & $\begin{array}{c}3.3 \mu \mathrm{g} / \mathrm{ml} \\
+++\end{array}$ & $\begin{array}{c}7 \mu \mathrm{g} / \mathrm{ml} \\
+++\end{array}$ & $\begin{array}{c}8 \mu \mathrm{g} / \mathrm{ml} \\
+++\end{array}$ & $\begin{array}{c}10 \mu \mathrm{g} / \mathrm{ml} \\
++\end{array}$ & $\begin{array}{c}10 \mu \mathrm{g} / \mathrm{ml} \\
+\end{array}$ \\
\hline Bovine & $\begin{array}{c}10 \mu \mathrm{g} / \mathrm{ml} \\
+++\end{array}$ & $\begin{array}{c}10 \mu \mathrm{g} / \mathrm{ml} \\
+++\end{array}$ & $\begin{array}{c}7 \mu \mathrm{g} / \mathrm{ml} \\
++\end{array}$ & $\begin{array}{c}8 \mu \mathrm{g} / \mathrm{ml} \\
++\end{array}$ & $\begin{array}{c}10 \mu \mathrm{g} / \mathrm{ml} \\
-\end{array}$ & $\begin{array}{c}10 \mu \mathrm{g} / \mathrm{ml} \\
-\end{array}$ \\
\hline Ovine & $\begin{array}{c}10 \mu \mathrm{g} / \mathrm{ml} \\
+++\end{array}$ & $\begin{array}{c}10 \mu \mathrm{g} / \mathrm{ml} \\
+++\end{array}$ & $\begin{array}{c}7 \mu \mathrm{g} / \mathrm{ml} \\
++\end{array}$ & $\begin{array}{c}8 \mu \mathrm{g} / \mathrm{ml} \\
++\end{array}$ & $\begin{array}{c}10 \mu \mathrm{g} / \mathrm{ml} \\
-\end{array}$ & $\begin{array}{c}10 \mu \mathrm{g} / \mathrm{ml} \\
-\end{array}$ \\
\hline $2^{\circ}$ antibody used & goat anti-rabbit & goat anti-rabbit & goat anti-mouse & goat anti-mouse & goat anti-mouse & goat anti-rabbit \\
\hline
\end{tabular}

(Fig 2g). ALP, BSP, ON, OPN and PINP immunolabelling of human bone was unsuccessful using heat-cured or coldcured LR White (Yang, 2003). Attempts at ON immunolabelling on sections of human bone standard embedded in MMA with $21^{\circ} \mathrm{C}$ polymerisation were also unsuccessful with no visible immunolabelling by either antibody (Yang, 2003). By using low-temperature Technovit 9100 New ${ }^{\circledR}$ embedding, a significant improvement in the OC immunolabelling signal was observed (Fig. 2i).

The Masson-Goldner staining method was again applied to Technovit 9100 New ${ }^{\circledR}$-embedded adult human bone sections to show the histomorphology to help interpretation of ensuing immunolabelled serial sections (Fig. 3a). The mineralised bone, osteoid, osteoblasts, osteocytes and haematopoietic tissue was observed. Osteoblasts were immunoreactive for ALP (Fig. 3b), PINP (Fig 3c), ON (Fig 3d), OPN (Fig. 3e) and BSP (Fig 3f). This was not observed with either standard MMA-embedded, cold or heat-cured LR White embedded adult human bone (Yang, 2003).

Monoclonal anti ovine PINP demonstrated the most exclusive immunolabelling of osteoblasts in human bone (Fig. 3c). PINP intensely and almost exclusively labelled osteoblasts with virtually no labelling of blood vessels, stromal cells, adipocytes, osteocytes, and mineralised bone. Monoclonal anti human ALP also provided relatively exclusive immunolabelling of osteoblasts (Fig. 3b). The osteoblasts and marrow stromal cells labelled intensely for ALP while blood vessels in the upper marrow cavity of the bone remained largely unlabelled. Monoclonal anti bovine $\mathrm{ON}$ labelled osteoblasts but with more pervasive labelling of the soft tissue as well (Fig. 3d). Mineralised bone and osteocytes were largely unlabelled for $\mathrm{ON}$. Polyclonal anti human OPN demonstrated the least specific immunolabelling (Fig. 3e). Though it labelled osteoblasts and cement lines intensely, it also labelled blood vessels, stromal cells, adipocytes, and osteocytes, with a low level of labelling throughout the mineralised bone (Fig 3e). The same was true of polyclonal anti human BSP though with weaker intensity than with anti OPN (Fig. 3f). BSP was, however, not immunolocalised in cement lines.
Antibodies (anti-mouse and anti-rabbit, see Table 2) demonstrated varying degrees of cross-reactivity between human, bovine and ovine bone (Table 2, Figs. 3, 4). The antibodies for OC, ON, PINP, and OPN also recognised epitopes in bovine (Fig. 4a-f) and ovine (Fig. 4g-l) bone. The antibodies for ALP and BSP that recognised epitopes in human bone (Fig. 3), did not recognise epitopes in bovine nor ovine bone.

Monoclonal and polyclonal antibodies against OC, OPN, ON, and PINP labelled bovine osteoblasts (Fig. 4af) and ovine osteoblasts (Fig. 4g-i) when embedded in Technovit. However higher concentrations were required compared to immunolabelling of human bone (Table 2). Monoclonal anti-human ALP and polyclonal anti-human BSP demonstrated little cross-reactivity with bovine or ovine bone (not shown). Apart from OC, all other matrix proteins were not immunolabelled in bovine or ovine bone embedded in LR White (Yang, 2003).

\section{Discussion}

This study has demonstrated that the low-temperature embedding methods significantly altered the staining properties of the resins. The soft tissue stained more intensely in LR White (heat-cured) embedded bones than cold-cured LR White. Cold-cured LR White sections did not adhere well to the glass slides compared to heat-cured LR White sections. Cold-cured LR White also contained more air bubbles trapped in the resin, possibly caused by pockets of heat within the resin during polymerisation damaging the tissue. This may be because the light does not catalyse the polymerisation of the resin homogenously throughout the resin. Rather, pockets of heat become concentrated within the resin and cause bubbles to form, damaging tissue constituents and greatly increasing the difficulty of obtaining good quality thin sections. The lowtemperature used for the Technovit $9100 \mathrm{New}{ }^{\circledR}$ embedding method altered the staining properties of the resin in comparison with conventionally-embedded MMA such that the Masson-Goldner stained nuclei were green in Technovit 9100 New ${ }^{\circledR}$ but red in standard MMA. The Technovit 9100 New ${ }^{\circledR}$ also displayed better morphological preservation of 
the undecalcified bone tissue than LR White, and was comparable to MMA.

In human tissue, OC immunolocalisation was highly specific for osteoblasts, as was expected since OC is the most bone-specific of the noncollagenous bone matrix proteins (Hughes and Aubin, 1998). Osteocalcin is expressed by osteoblasts late in the differentation process, and is not expressed by osteoblast-precursor cells or adipocytes, (Hughes and Aubin, 1998). It has been reported that osteocytes produce high levels of OC, even higher than osteoblasts and that this may be linked to an attempt by the osteocytes to prevent the mineralisation of the osteoid tissue immediately surrounding them to allow increased diffusion of nutrients and waste products to and from the cell (Mikuni-Takagaki et al., 1995). OC is now also used as an osteocyte-specific in vitro marker (Kato et al., 1997). $\mathrm{ON}$ is expressed by many cells other than osteoblasts. This fact was demonstrated by immunolocalisation of low levels of ON to blood vessels and soft tissue. It has been reported from immunohistochemical studies that young osteocytes express ON (Jundt et al., 1987), but little immunolocalisation of $\mathrm{ON}$ to osteocytes was observed in this study with adult human bone. Although BSP and OPN were both immunolabelled with polyclonal antisera, antiBSP demonstrated much weaker immunolabelling than anti-OPN, even though both proteins are structurally similar and contain the RGD domain. There are a number of possible explanations for this: BSP is expressed in a more restricted fashion than OPN (Robey, 1996) which could mean that fewer osteoblasts are expressing it at any given time. BSP expression is tightly associated to mineral production that perhaps it was expressed much less than OPN, or that the epitope that the BSP antisera targeteted was more delicate than the epitope that OPN antisera targets. It is possible that the fixation process somehow masks or destroys this more delicate or fixation-sensistive epitope. More tests will have to be carried out with this bone matrix marker to improve immunolabelling.

The majority of the antibodies demonstrated cross-reactivity between the three species (human, bovine and ovine) investigated in this work, with the notable exceptions of anti-human ALP (B4-78) and anti-human BSP (LF-120). This suggests a high degree of conservation of antibody-recognised epitopes between the bone matrix proteins. In the case of the two antibodies that did not work, the fact that B4-78 and LF-120 did not cross-react with either bovine or ovine tissue was likely because the epitopes that these antibodies recognised were found only in human tissue. It is highly unlikely that it was due to there being no ALP or BSP present in the bovine or ovine tissue for the antibody to bind. The fact that anti-human ALP did not recognize bovine or ovine ALP could be partly due to it being a monoclonal antibody. However, this does not explain why the polyclonal antibody anti-human BSP also did not recognise BSP in bovine or ovine tissue. Both antibodies were IgG so it is not likely that the weaker labelling of even the human ALP and BSP was due to the antibody being too large a constituent for the targeted epitope.

The most plausible reason for the significantly lower immunohistochemical sensitivity of LR White sections was the fact that LR White cannot be deacrylated and thus only surface levels expose epitopes as antigens. In a study comparing glycol methacrylate (Technovit 7100) and MMA (Technovit 9100) in situ hybridisation, it was demonstrated that Technovit 9100 (which can be deacrylated) showed higher in situ sensitivity than Technovit 7100 (which cannot be deacrylated) (Saito et al., 1998). A similar principle could be extrapolated to LR White. There was also likely little penetration of the antibody into the resin. Previous work with LR White demonstrated that there is so little penetration of aqueous solutions into LR White that it is possible to perform immunolabelling against one antigen on one side of a section and another antigen on the other side of a section without any cross-labelling (Brorson et al., 1994)).

Another possible explanation for the reduced immunohistochemical labelling of both heat-cured LR White and standard MMA-embedded material is that the catalyst dibenzoyl peroxide may have damaged antigenicity of the tissue during the polymerisation process. At $50^{\circ} \mathrm{C}$, dibenzoyl peroxide breaks down and releases free radicals which are highly destructive to proteins, and which catalyse the polymerisation, or cross-linking, of LR White and MMA. However, such an explanation would not explain why cold-cured LR White (which did not contain any dibenzoyl peroxide) demonstrated even less immunohistochemical labelling than heat-cured LR White. Heat-cured LR White at least demonstrated low levels of OC immunolocalisation in osteoblasts and cold-cured LR White did not. Also, cold-cured MMA (Technovit 9100 New $\left.{ }^{\circledR}\right)$ also contains dibenzoyl peroxide as one of the catalysts but at four times less the concentration $(0.5 \%)$ than in heat-cured LR White and standard MMA (2\%). Also, Technovit 9100 New ${ }^{\circledR}$ contains a second catalyst, N,N-3,5-tetramethylaniline, and a regulator, decane-1thiol, which slow down the rate of polymerisation and release of free radicals by the primary catalyst of reaction, dibenzoyl peroxide.

The study demonstrated antigenic preservation in undecalcified trabecular bone following the embedding Technovit 9100 New ${ }^{\circledR}$ embedding method utilising the chemical accelerator N,N-3,5-tetramethylaniline. Bone embedded with this method demonstrated immunohistochemical preservation of six bone matrix proteins, osteocalcin, alkaline phosphatase, osteopontin, bone sialoprotein, osteonectin and Pro-collagen type 1 aminopropeptide.

Factors explaining the immunolabelling differences between heat- and cold-cured LR White may involve more than just preservation of antigenicity. One possibility is that blue-light initiated cold-curing caused a higher density cross-linking of LR White creating a more hydrophobic resin that prevented the penetration of aqueous solutions like antibodies in a buffer or aqueous staining solutions for histology. Another possibility is that the bluelight initiated cold curing method may not have allowed for an even dispersal of heat during polymerisation but rather created concentrated pockets of highly exothermic polymerisation within the tissue resulting in increased antigenic damage. Often polymerised samples exhibited numerous bubbles trapped within the bone which were not 
evident in heat-cured samples. This observation suggests that the release of heat from polymerisation was not controlled as well as had been hoped in a $-20^{\circ} \mathrm{C}$ chamber.

It is important to note though that some literature suggests that sub-zero polymerisation temperature is not essential for retaining immunohistochemical and enzymatic preservation in MMA. Polymerisation of MMA at 19$22^{\circ} \mathrm{C}$ yielded enzymatic preservation of chloracetate esterase, elastase, lysozyme, factor VIII-related-antigen, GPIIIA, CD45, MB1, MT1, Ki-67 and others (Bernhards et al., 1992; Georgii et al., 1995; Lebeau et al., 1995). Even polymerisation of MMA at $40^{\circ} \mathrm{C}$ yielded immunolabelling of human collagen type I, III, IV, fibronectin, and antilaminin (Lucena et al., 1997). However, many groups report that conventional MMA embedding (polymerisation temperatures between $25-40^{\circ} \mathrm{C}$ ) does not reliably preserve enzymatic and antigenic activity (Erben, 1997) and therefore near or sub-zero MMA polymerisation methods have been sought.

Previous sub-zero MMA polymerisation methods have only been reported by Wolf et al. (Wolf et al., 1992) who developed an embedding method that allowed reliable $15^{\circ}$ to $-20^{\circ} \mathrm{C}$ polymerisation with the addition of the chemical accelerator $\mathrm{N}, \mathrm{N}$-dimethyl- $p$-toluidine in addition to benzoyl peroxide. This was subsequently used to demonstrate alkaline phosphatase, osteocalcin, osteonectin, and CD34 immunohistochemical preservation in human bone (Hauge et al., 2001).

This study demonstrates that Technovit 9100 New ${ }^{\circledR}$ has the potential to be used as a routine embedding method for undecalcified bone immunohistochemistry and histology.

\section{Conclusions}

Bone embedded in Technovit 9100 New ${ }^{\circledR}$ yielded more reliable immunolabelling of the bone matrix proteins compared with either heat or cold-cured LR White or with standard embedded MMA samples. Other antibodies against ALP and BSP should be tested to determine a better means of immunolabelling bovine and ovine ALP and BSP since the ALP and BSP antibodies used in this work provided insufficient immunolabelling of bovine and ovine ALP and BSP. Technovit $9100 \mathrm{New}{ }^{\circledR}$ also provided better routine histology than LR White, and was comparable to MMA. Results demonstrated that Technovit 9100 New ${ }^{\circledR}$ can be used as a low-temperature acrylic resin (MMA) embedding method for routine undecalcified bone immunohistochemistry and histomorphology.

\section{Acknowledgements}

The authors would like to thank Dr. Thomas Perren, CoChefarzt of the Department of Orthopaedics and Surgery, Davos Hospital for the human bone, as well as Professor Berton Rahn, Nora Goudsouzian and Regula Mueller (AO Research Institute) for helpful assistance and discussions.

\section{References}

Arana-Chavez VE, Nanci A (2001) High-resolution immunocytochemistry of noncollagenous matrix proteins in rat mandibles processed with microwave irradiation. J Histochem Cytochem 49:1099-1109.

Arai N, Ohya K, Ogura H (1993) Osteopontin mRNA expression during bone resorption: an in situ hybridization study of induced ectopic bone in the rat. Bone Miner 22: $129-145$.

Arnold WH, Gaengler P, Kalkutschke L (1998) Threedimensional reconstruction of approximal subsurface caries lesions in deciduous molars. Clin Oral Investig 2: 174179.

Arnold WH, Konopka S, Gaengler P (2001) Qualitative and quantitative assessment of intratubular dentin formation in human natural carious lesions. Calcif Tissue Int 69: 268-273.

Arnold WH, Konopka S, Kriwalsky MS, Gaengler P (2003) Morphological analysis and chemical content of natural dentin carious lesion zones. Ann Anat 185: 419424.

Bernhards J, Weitzel B, Werner M, Rimpler M, Georgii A (1992). A new histological embedding method by lowtemperature polymerisation of methyl methacrylate allowing immuno- and enzyme histochemical studies on semithin sections of undecalcified bone marrow biopsies. Histochem 98: 145-154.

Bianco P, Silvestrini G, Termine J, Bonucci E (1988) Immunohistochemical localization of osteonectin in developing human and calf bone using monoclonal antibodies. Calcif Tissue Int 43: 155-161.

Bhattacharyya TK, Sanchez B, Toriumi D (2000) Evaluation of LR white resin for histology of the undecalcified rat tibia. Biotech Histochem 75: 7-14.

Bolander ME, Gehron-Robez P, Fisher LW, Conn KM, Prabhakar BS, Termine JD (1989) Monoclonal antibodies against osteonectin show conservation of epitopes across species. Calcif Tissue Int 45: 74-80.

Bord S, Vedi S, Beavan SR, Horner A, Compston JE (2000) Megakaryocyte population in human bone marrow increases with estrogen treatment: a role in bone remodeling? Bone 27: 397-401.

Bronckers A, Gay S, Finkelman R, Butler W (1987) Developmental appearance of Gla proteins (osteocalcin) and alkaline phosphatase in tooth germs and bones of the rat. J Bone Miner Res 2: 361-373.

Bronckers A, Farach-Carson M., van Waveren E, Butler W (1994) Immunolocalization of osteopontin, osteocalcin, and dentin sialoprotein during dental root formation and early cementogenesis in the rat. J Bone Miner Res 9: 833-841.

Brorson SH, Roos N, Skjorten F (1994) Antibody penetration into LR-White sections. Micron 25: 453-460.

Burkhardt R (1966) Preparatory conditions for clinical histology of human bone marrow. 2. A new procedure for histological preparation of bone and bone marrow biopsies (in German). Blut 14: 30-46.

Chappard D, Alexandre C, Camps M, Montheard JP, Riffat G (1983) Embedding iliac bone biopsies at low tem- 
perature using glycol and methyl methacrylates. Stain Technol 58: 299-308.

Chappard, D, Palle, S, Alexandre, C, Vico, L, Riffat, $\mathrm{G}$ (1987) Bone embedding in pure methyl methacrylate at low temperature preserves enzyme activities. Acta histochem 81:183-190.

Erben RG (1997) Embedding of bone samples in methyl methacrylate: an improved method suitable for bone histomorphometry, histochemistry, and immunohistochemistry. J Histochem Cytochem 45: 307-313.

Fisher LW, Stubbs JT, Young MF (1995) Antisera and cDNA probes to human and certain animal model bone matrix noncollagenous proteins. Acta Orthop Scand (Suppl 266) 66: 61-65.

Foellmer HG, Kawahara K, Madri JA, Furthmayr H, Timpl R, Tuderman L (1983) A monoclonal antibody specific for the amino terminal cleavage site of procollagen type I. Eur J Biochem 134: 183-189.

Georgii A, Bernhards J, Werner M (1995). Die neue Hannover-methode zur kunststoffeinbettung von knochenmark: kaltpolymerisation von methylmethacrlyat (The new Hannover method for plastic embedding of bone marrow: cold polymerization of methylmethacrylate). Pathologe 16: 28-33.

Hauge EM, Qvesel D, Eriksen EF, Mosekilde L, Melsen F (2001). Cancellous bone remodeling occurs in specialized compartments lined by cells expressing osteoblastic markers. J Bone Mineral Res 16:1575-1582.

Hughes FJ, Aubin JE (1998) Culture of cells of the osteoblast lineage. In: Methods in Bone Biology. Arnett TRHB (ed.). Chapman and Hall, London. pp 1-39.

Ingram RT, Clarke BL, Fisher LW, Fitzpatrick LA (1993) Distribution of noncollagenous proteins in the matrix of adult human bone: evidence of anatomic and functional heterogeneity. J Bone Min Res 8:1019-1029.

Jundt G, Berghaeuser K, Termine J, Schulz A (1987) Osteonectin - a differentiation marker of bone cells. Cell Tissue Res 248: 409-415.

Kato Y, Windle JJ, Koop BA, Mundy GR, Bonewald LF (1997). Establishment of an Osteocyte-like cell line, MLO-Y4. J Bone Mineral Res 12: 2014-2023.

Lawson GM, Katzman JA, Kimlinger TK, O'Brien JF (1985) Isolation and preliminary characterization of a monoclonal antibody that interacts preferentially with the liver isoenzyme of human alkaline phosphatase. Clin Chem 31: 381-385.

Lebeau A, Muthmann H, Sendelhofert A, Diebold J, Löhrs U (1995) Histochemistry and immunohistochemistry on bone marrow biopsies: a rapid procedure for methyl methacrylate embedding. Path Res Pract 191:121129.

Liu C (1987). A simplified technique for low temperature methyl methacrylate embedding. Stain Technol 62:155159.

Lucena SB, Duarte MEL, Fonseca EC (1997). Plastic embedded undecalcified bone biopsies: an immunohistochemical method for routine study of bone marrow extracellular matrix. J Histotechnol 20: 253-257.

Miao D, Bai X, Panda D, McKee M, Karaplis A, Goltzman D (2001) Osteomalacia in hyp mice is associ- ated with abnormal phex expression and with altered bone matrix protein expression and deposition. Endocrinology 142: 926-939.

Mikuni-Takagaki Y, Kakai Y, Satohoshi M, Kawano E, Suzuki Y, Kawase T, Saito S (1995). Matrix mineralisation and the differentiation of osteocyte-like cells in culture. J Bone Miner Res 10: 231-242.

Newman GR, Jasani B, Williams ED (1982). The preservation of ultrastructure and antigenicity. J Microsc 127: RP5-RP6.

Newman GR, Hobot JA (2001) Resin Microscopy and On-Section Immunocytochemistry, 2nd ed., SpringerVerlag, Berlin Heidelberg New York.

Park YK, Yang MH, Park HR (1996) The impact of osteonectin for differential diagnosis of osteogenic bone tumors: an immunohistochemical and in situ hybridization approach. Skeletal Radiol 25: 13-17.

Parker CR, Freemont AJ, Blackwell PJ, Grainge MJ, Hosking DJ (1999) Cross-sectional analysis of renal transplantation osteoporosis. J Bone Miner Res 14: 1943-1951.

Rauch F, Lauzier D, Croteau S, Travers R, Glorieux FH, Hamdy R (2000) Temporal and spatial expression of bone morphogenetic protein-2, -4 , and -7 during distraction osteogenesis in rabbits. Bone 27: 453-459.

Richards RG, Stiffanic M, Owen GRh, Riehle M, ap Gwynn I, Curtis ASG (2001) Immunogold labelling of fibroblast focal adhesion sites visualised in fixed material using scanning electron microscopy and in vivo, using Internal Reflection Microscopy. Cell Biol Int 25: 12371249.

Robey PM (1996). Bone matrix proteoglycans and glycoproteins. In Principles of Bone Biology. Bilezikian JP, Raisz LG, Rodan GA (eds.). Academic Press, London. pp 155-165.

Ruddell CL (1967) Hydroxyethyl methacrylate combined with polyethylene glycol 400 and water; and embedding medium for routine 1-2 micron sectioning. Stain Technol 42: 119-123.

Saito C, Hayashi M, Sakai A, Fujie M, Kuroiwa H, Kuroiwa T (1998) Improved Sensitivity for high resolution in situ hybridization using resin extraction of methyl methacrylate embedded material. Biotechnic Histochem 74: 40-48.

Sanderson C (1997) Entering the realm of mineralized bone processing: a review of the literature and techniques. J Histotechnol 20: 259-266.

Schenk R (1965) On the histological processing of undecalcified bone. Acta Anat (Basel), 60: 3-19.

Semba I, Ishigami T, Sugihara K, Kitano M. (2000) Higher osteoclastic demineralization and highly mineralized cement lines with osteocalcin deposition in a mandibular cortical bone of autosomal dominant osteopetrosis type II: ultrastructural and undecalcified histological investigations. Bone 27: 389-395.

Stafford H, Roberts M, Oni O, Hay J, Gregg P (1994) Localisation of bone-forming cells during fracture healing by osteocalcin immunocytochemistry: An experimental study of the rabbit tibia. J Orthop Res 12: 29-39.

Strehblow C, Gyongyosi M, Sperker W, Shirazi M, Windberger U, Pugatsch T, Ben-Sasson S, Lotan C, Glogar 
D (2002) Usefulness of intravascular ultrasound-guided histological measurements after stenting in porcine coronary artery. Coron Artery Dis 13: 291-294.

Te Velde J, Haak HL (1977) Aplastic anaemia. Histological investigation of methacrylate embedded bone marrow biopsy specimens; correlation with survival after conventional treatment in 15 adult patients. Br J Haematol, 35: 61-69.

Technovit 9100 New ${ }^{\circledR}$ Product Brochure, Heraeus Kulzer GmbH Co. KG, ++49-6081-959-0, http:// www.Kulzer-Technik.de. 2001. (Pamphlet).

Thomsen JS, Ebbesen EN, Mosekilde L (1998) Relationships between static histomorphometry and bone strength measurements in human iliac crest bone biopsies. Bone 22: 153-163.

Vedi S, Shaun G, Skingle SJ, Garrahan NJ, Ninkovic M, Alexander GA, Compston JE (1999) Mechanism of bone loss after liver transplantation: a histomorphometric analysis. J Bone Min Res 14: 281-287.

Westen H, Muck KF, Post L (1981) Enzyme histochemistry on bone marrow sections after embedding in methacrylate at low temperature. Histochemistry, 70: 95105.

Wolf E, Röser K, Han M, Welkerling H, Delling G (1992). Enzyme and immunohistochemistry on undecalcified bone and bone marrow biopsies after embedding in plastic: a new embedding method for routine application. Virchows Arch A 420: 17-24.

Yang. R (2003) Evaluation of Technovit 9100 New and LR White resins for Undecalcified Trabecular Bone Histology and Immunohistochemistry. M.Phil. Dissertation. University of Wales.

Yoshimura N, Murachi T, Heath R, Kay J, Jasani B, Newman GR (1986). Immunogold electron microscopic localization of calpain I in skeletal muscle of rats. Cell Tissue Res 244: 265-270.

\section{Discussion with Reviewers}

H. Plenk: Do you have already experiences with inclusion of implant (material)s into these bones, then preparation of microtome and/or ground sections, and then application of routine and (immuno)histochemical staining procedures?

Authors: The work we present here is our first work with Technovit 9100 New ${ }^{\circledR}$ resin for immunohistochemical procedures. We have previously worked with this resin for histomorphological studies (unpublished) and we have not worked as of yet with implants (metal, ceramic or polymer) with this resin. We have not attempted any grinding of Technovit 9100 New ${ }^{\circledR}$ sections yet. The AO Research In- stitute histology laboratory has had between 35-40 years experience with sectioning MMA embedded metal implants with bone and soft tissue and at least 15 years experience with sectioning of MMA embedded polymer and ceramic implants and more recently LR White embedded ones. We do intend to start though!

P. Rooney: The paper may have benefited by comparing the morphology of the samples with that obtained from de-calcified paraffin sections.

Authors: This is a good point and should be considered for future work.

J. Gasser: Radical formation from dibenzoyl peroxide is indeed a known problem. Did you make an attempt to reduce the concentration of the catalyst

Authors: We did not reduce the concentration of dibenzoyl peroxide in the MMA in this study, but as you mention this may well improve immunolabelling with MMA. The cold-cured LR white did not use dibenzoyl peroxide as a catalyst and had poorer immunolabelling results than the heat-cured LR White that did contain dibenzoyl peroxide, but possibly the benzyl catalyst had even worse effect.

J. Gasser: Expression of osteocalcin is higher in osteocytes than in osteoblasts. Do you have any explanation why you get a decent signal in osteoblasts but not in osteocytes?

Authors: The immunolabelling of osteocalcin was observed in both osteocytes and osteoblasts and appears to be more intense in the osteoblasts, but this is more qualitative than quantitative. It may well be worth us retrying our paraformaldehyde fixation method (possibly varying times and temperatures) with our optimised immunolabelling method with the Technovit $9100 \mathrm{New}{ }^{\circledR}$ resin for a few of the antibodies. Many methods can be used for immunolabelling and we only show our optimised method for immunogold labelling. In another study (Müller, 2003) we have looked at immunofluorescent labelling, but had problems with autofluorescnce of human bone tissue as well as signal bleaching and several other problems and found here that the immunogold labelling did not have such problems.

\section{Additional Reference}

Müller R. (2003) Immunological identification of the osteoclast formation regulator osteoprotegerin ligand (OPGL/RANKL/TRANCE). M.Sc. Dissertation. University Medical Centre, Nijmegen, Netherlands. 